\title{
Food insecurity in pregnant women is associated with social determinants and nutritional outcomes: a systematic review and meta-analysis
}

\author{
Associação entre insegurança alimentar, determinantes sociais e \\ desfechos nutricionais em mulheres grávidas: revisão e metanálise
}

Fran Demétrio (https://orcid.org/0000-0001-8231-3307) ${ }^{1}$

Carlos Antônio de Souza Teles (http://orcid.org/0000-0003-0970-0479) ${ }^{2}$

Djanilson Barbosa dos Santos (https://orcid.org/0000-0002-6128-1155) ${ }^{1}$

Marcos Pereira (https://orcid.org/0000-0003-3766-2502) ${ }^{3}$

${ }^{1}$ Cento de Ciências da Saúde, Universidade Federal do Recôncavo da Bahia. R. Carlos Amaral 1.015, Cajueiro. 44574-490 Santo Antônio de Jesus BA Brasil. frandemetrio7@gmail.com

${ }^{2}$ Instituto Gonçalo Moniz, Fiocruz. Salvador BA Brasil.

${ }^{3}$ Instituto de Saúde Coletiva, Universidade Federal da Bahia. Salvador BA Brasil.

\begin{abstract}
The association between FI, social determinants, and nutritional outcomes for pregnant women are analyzed. A systematic review was conducted through a search of articles in five electronic databases. Social determinants (race, education, participation in social programs) and nutritional status (pre-gestational BMI, gestational weight gain, anemia) were analyzed in relation to the FI situation. For each article, the frequency of food insecurity was collected in order to calculate the summary measure, prevalence ratio (PR). 26 articles were selected. An elevated occurrence of FI was associated with black pregnant women (PR: 1.83, 95\% CI 1.08-3.10), participation in social protection programs $(P R=1.43$, 1.02-2.01), and with low education levels on the part of pregnant women $(P R=2.73,1.68-4.43)$. FI increased the chances of being overweight ( $P R$ $=1.57,95 \% C I=1.29-1.91)$ and obese $(P R=$ $1.47,95 \% C I=1.15-1.87)$ in pregnant women, as well as excessive weight gain ( $P R=1.42,95 \%$ $C I=1.10-1.82)$ and inadequate weight gain $(P R$ $=1.47 ; 95 \% C I=1.09-1.97)$ during pregnancy. Anemia was not associated with FI. Social inequities are associated with food and nutritional insecurity in pregnant women.
\end{abstract}

Key words Food and nutritional security, Pregnant women, Social determinants of health
Resumo O estudo objetiva analisar a associação entre insegurança alimentar, determinantes sociais e estado nutricional de mulheres gestantes por meio de uma revisão sistemática e metanálise. As buscas de artigos ocorreram em cinco bases eletrônicas. Determinantes sociais (raça, escolaridade, participação em programa social) e estado nutricional (IMC pré-gestacional, ganho de peso gestacional, anemia) foram analisados em relação à situação de IA. Em cada estudo, a frequência de insegurança alimentar foi coletada para calcular a medida sumário- razão de prevalência $(R P)$ e seu intervalo de confiança de 95\%(IC95\%). Foram selecionados 26 artigos. Observou-se elevada ocorrência de IA em gestantes pretas (RP:1,83; IC 95\% 1,08-3.10), naquelas com participação em programas de proteção social $(R P=1.43$; IC $95 \%=1.02-2.01)$ e com baixo nivel de escolaridade $(R P=2.73 ;$ IC $95 \%=1.68-4.43)$. O fato de a gestante possuir companheiro protegeu contra IA $(R P=0.61 ;$ IC $95 \%=0.40-0.95)$. A experimentação da IA elevou a chance de sobrepeso $(R P=$ 1.57; IC $95 \%=1.29-1.91)$ e de obesidade $(R P=$ 1.47; IC 95\% = 1.15-1.87), assim como o ganho excessivo $(R P=1.42$; IC $95 \%=1.10-1.82)$ e inadequado ( $R P=1.47$; IC 95\%= 1.09-1.97) de peso na gestação. Iniquidades sociais estão associadas a IA em gestantes.

Palavras-chave Determinantes sociais da saúde, Mulheres grávidas, Segurança alimentar e nutricional 


\section{Introduction}

Food insecurity (FI) is a significant risk factor that can influence the physical health of both the pregnant woman and her child, directly compromising the nutritional state and serum profile of micronutrients, such as iron ${ }^{1,2}$. It may also trigger a series of stressful events in the family environment due to the difficulty in obtaining food, provoking a deterioration in maternal mental health and consequent development of anxiety and depression, and also leading to negative repercussions with regard to childcare ${ }^{3}$.

FI consists of the violation of the human right to adequate food (HRAF). In other words, the lack of adequate food, both from a quantitative and qualitative perspective, can deny one the right to life $e^{4}$ The light and moderate forms of FI involve concern or uncertainty with regard to food access and inadequate food quality, and quantitative reduction of food among adults and children and/or a rupture in food standards resulting from the lack of food, respectively. Serious $\mathrm{FI}$, in addition to these aspects, is marked by the presence of hunger, where someone may spend an entire day without eating due to lack of money with which to purchase food ${ }^{5}$.

FI status worldwide has shown some improvements in recent years. The number of people experiencing FI globally decreased from $18.6 \%$ to $12.5 \%$ between $1990-92$ and $2010-12$, and dropped from $23.2 \%$ to $14.9 \%$ in developing countries, indicating the possibility of hitting the Millennium Development Goal (MDG) target, should all adequate and appropriate actions be taken ${ }^{6}$.

Adequate food for women, especially during the gestational phase, is a critical factor for improved health and quality of life. It contributes to a reduction in gestational complications and maternal and neonatal mortality; to nutritional status and adequate maternal weight gain; to normal levels of micronutrient serum concentrations, such as iron; and to satisfactory obstetric results, such as adequate birth weight and gestational age at birth ${ }^{7-10}$.

Food insecurity in pregnant women is related to the social health determinants. This is because social inequities lead to disparities in health and nutrition $^{11,12}$, especially during the gestational phase. In this sense, social determinants such as race, education level, and the existence of social protection policies have a determinative effect on the condition of food security.

On the other hand, no meta-analyses were found in the epidemiological literature about the association between food insecurity, social determinants, and nutritional outcomes among pregnant women. It is therefore important to aggregate and systematize information about FI and its relationship to social determinants and nutritional state, in order to provide information that will support future studies and public policies that promote and guarantee women's food and nutritional security (FNS). The current study was designed with this objective in mind.

\section{Methods}

\section{Registration and protocol}

A systematic review and meta-analysis were carried out, following PRISMA standards ${ }^{13}$, in order to answer the following key question: "What is the association between food insecurity and social and nutritional determinants in pregnant women, when compared against women who have food security?" To answer this question, the scientific literature related to the interface between FNS and gestational health was reviewed and the protocol for this systematic review was registered in PROSPERO.

\section{Search strategy}

Two researchers (MP and FD) independently searched the Medline/PubMed, Web of Science, Scopus, Science Direct, and Lilacs databases between April 2016 and July 2017 using search terms "food and nutritional insecurity" combined with "pregnant women", "pregnancy", and "women's health" (Chart 1). The publications were located based on the combination of these search terms and the key question. The reference list of relevant articles was then manually searched to identify additional articles.

Articles in Portuguese, English, and Spanish published from 2000 that used a validated food security assessment tool were screened. The published papers were managed using the Mendeley ${ }^{\circledR}$ program.

\section{Eligibility criteria}

The inclusion and exclusion criteria used are highlighted in Chart 2. Publications identified in the databases were selected independently by two reviewers (MP and FD) using forms containing the eligibility criteria for the studies. Publications 
Chart 1. Database search strategy and results.

\begin{tabular}{|c|c|c|}
\hline Database & Search strategy & $\begin{array}{l}\text { Items } \\
\text { found }\end{array}$ \\
\hline $\begin{array}{l}\text { Medline/PubMed } \\
\text { http://www.ncbi.nlm. } \\
\text { nih.gov/pubmed }\end{array}$ & $\begin{array}{l}\text { "food insecurity"[All Fields] OR “food security”[All Fields]) AND (“pregnant } \\
\text { women”[All Fields] OR “women”[All Fields]) AND ((“2000/01/01”[PDAT] : } \\
\text { “3000/12/31”[PDAT]) AND “humans"[MeSH Terms]) }\end{array}$ & 524 \\
\hline $\begin{array}{l}\text { Web of science- } \\
\text { http://apps- } \\
\text { webofknowledge.ez }\end{array}$ & $\begin{array}{l}\text { ((“food insecurity” OR “food security”) AND (“pregnant women” OR } \\
\text { “women”)) } \\
\text { OR LIMIT-TO: ( 2016 OR } 2010 \text { OR 2004 OR 2015 OR } 2007 \text { OR } 2002 \text { OR } \\
2014 \text { OR 2009 OR 2001 OR } 2013 \text { OR 2008 OR } 2012 \text { OR } 2006 \text { OR } 2000 \text { OR } \\
2011 \text { OR 2003 OR 2017 OR 2005 ) }\end{array}$ & 1.328 \\
\hline $\begin{array}{l}\text { Scopus: http://www. } \\
\text { scopus.com/ }\end{array}$ & 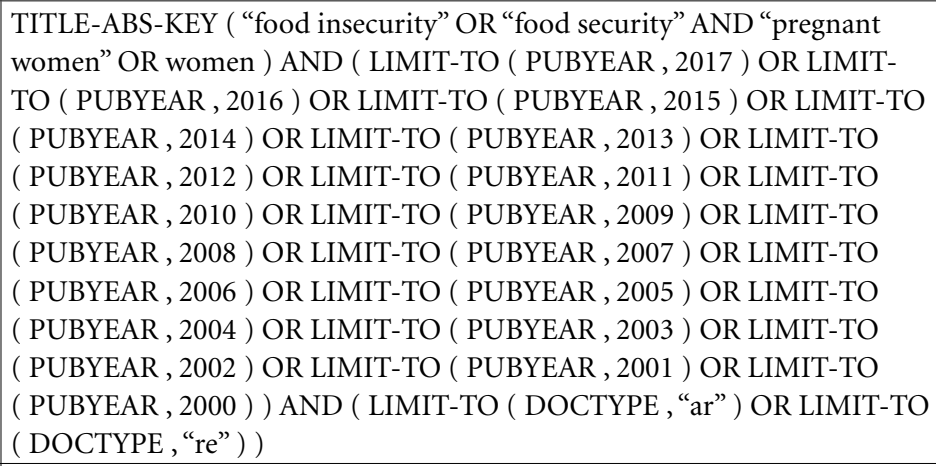 & 1193 \\
\hline $\begin{array}{l}\text { Science Direct: http:// } \\
\text { www.sciencedirect.com/ }\end{array}$ & food insecurity AND pregnant women OR women & 1.329 \\
\hline Lilacs & food insecurity AND pregnant women OR women & 8 \\
\hline
\end{tabular}

Chart 2. Eligibility criteria employed.

\begin{tabular}{|l|l|}
\hline \multicolumn{1}{|c|}{ Inclusion criteria } & \multicolumn{1}{c|}{ Exclusion criteria } \\
\hline Population: pregnant women at any gestational age & Studies focusing on other group \\
\hline $\begin{array}{l}\text { Study identified as cross-sectional, cohort, and case- } \\
\text { control, intervention. }\end{array}$ & Qualitative sudies \\
\hline Portuguese, English, and Spanish languages & $\begin{array}{l}\text { Types of documents were not considered: editorials, } \\
\text { letters, articles of opinion, comments, management } \\
\text { reports, official documents from national and } \\
\text { international programs and books }\end{array}$ \\
\hline $\begin{array}{l}\text { Published from 1st January 2010 to 10th July 2017 } \\
\text { (online or in print) }\end{array}$ & $\begin{array}{l}\text { Outcomes: food insecurity in pregnant nutritional } \\
\text { outcomes }\end{array}$ \\
\hline
\end{tabular}

were screened based on their titles and abstracts. If they met the selection criteria, they were then selected for a full-text review. Following the review, articles about which opinions diverged were selected by a consensus reached between the reviewers.

\section{Data extraction process}

The articles selected were read in their entirety and the following information was extracted and recorded using a specially designed form: publication and design objective of the study, sample size, age of participants, time pe- 
riod when the study was conducted, instrument/ method used to evaluate food insecurity, location, and outcome(s) investigated.

Data on the prevalence of food security and insecurity for pregnant women were collected for each result of interest. For the results related to social determinants, data was collected for the following groups: race/color (black, non-black), education level ( $>$ high school, < high school), marital status (married, unmarried), and participation in social programs (yes, no). Nutritional results data was collected for the following groups: anemic (yes, no), pre-gestational BMI, overweight (yes, no), obese (yes, no), and weight gain during pregnancy, categorized as either inadequate (yes, no) or excessive (yes, no).

\section{Assessing bias risk}

Bias risk was assessed according to the Research Triangle Institute Item Bank (RTI-Item Bank) ${ }^{14}$. The RTI-Item Bank contains items for evaluating observational studies, seven of which are applicable to the studies included in this review. This tool considers uniform inclusion/ exclusion criteria, appropriate sample selection, valid assessment of inclusion/exclusion, and valid assessment of outcome (Chart 3). Domain details for each tool are available elsewhere ${ }^{14}$. If a study obtained one or more negative responses, it was considered to have a high bias risk. If one or more "partially" or "cannot be determined" outcomes were observed, the study was considered to have a moderate bias risk. Low bias risk was defined for cases where all study questions had a positive response.

\section{Statistical analysis}

The prevalence ratio (PR) was used to summarize the meta-analysis and the results are presented in a Forest Plot chart. PR and its respective confidence interval $(95 \% \mathrm{CI})$ were obtained following the fixed or random effects model, depending on the heterogeneity between the studies $^{15}$. The heterogeneity and inconsistency of the measures were identified using the Cochran- $\mathrm{Q}$ statistical test. Where heterogeneity was confirmed, the random effects model analysis was performed with inverse variance, weighted by the results of the individual studies ${ }^{15}$. The inconsistency test $\left(\mathrm{I}^{2}>50 \%\right)$ was used as an indicator of elevated heterogeneity ${ }^{15}$.

In all analyses, a p-value of less than 0.05 was considered statistically significant. Statistical analysis was performed using the Stata 13 program (Stata Corp, College Station, TX, USA) and the PR was obtained using the metan command.

\section{Results}

\section{Identification and characteristics of eligible studies}

An initial search generated a list of 4382 publications in the selected databases, 271 of which were duplicates. After screening, 124 articles were assessed for eligibility and 98 were excluded because they did not meet the inclusion criteria. Therefore, 26 studies ${ }^{1,10,16-39}$ were eligible for inclusion in the systematic review and 11 were eligible for the meta-analyses (Figure 1).

Chart 3. RTI Item Bank use in the Present Systematic Review.

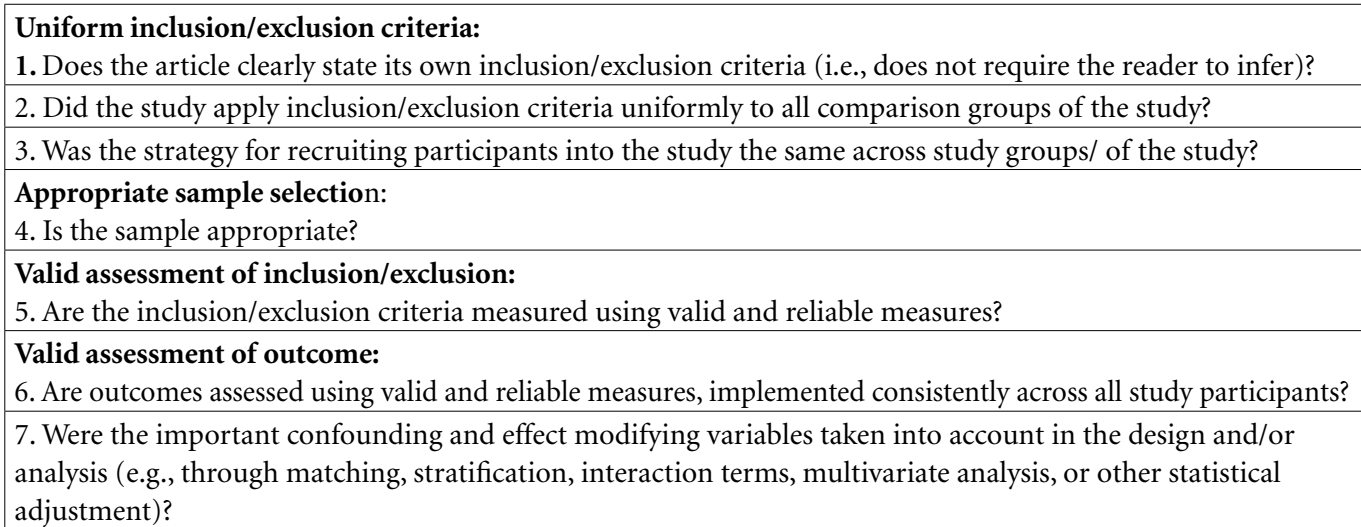




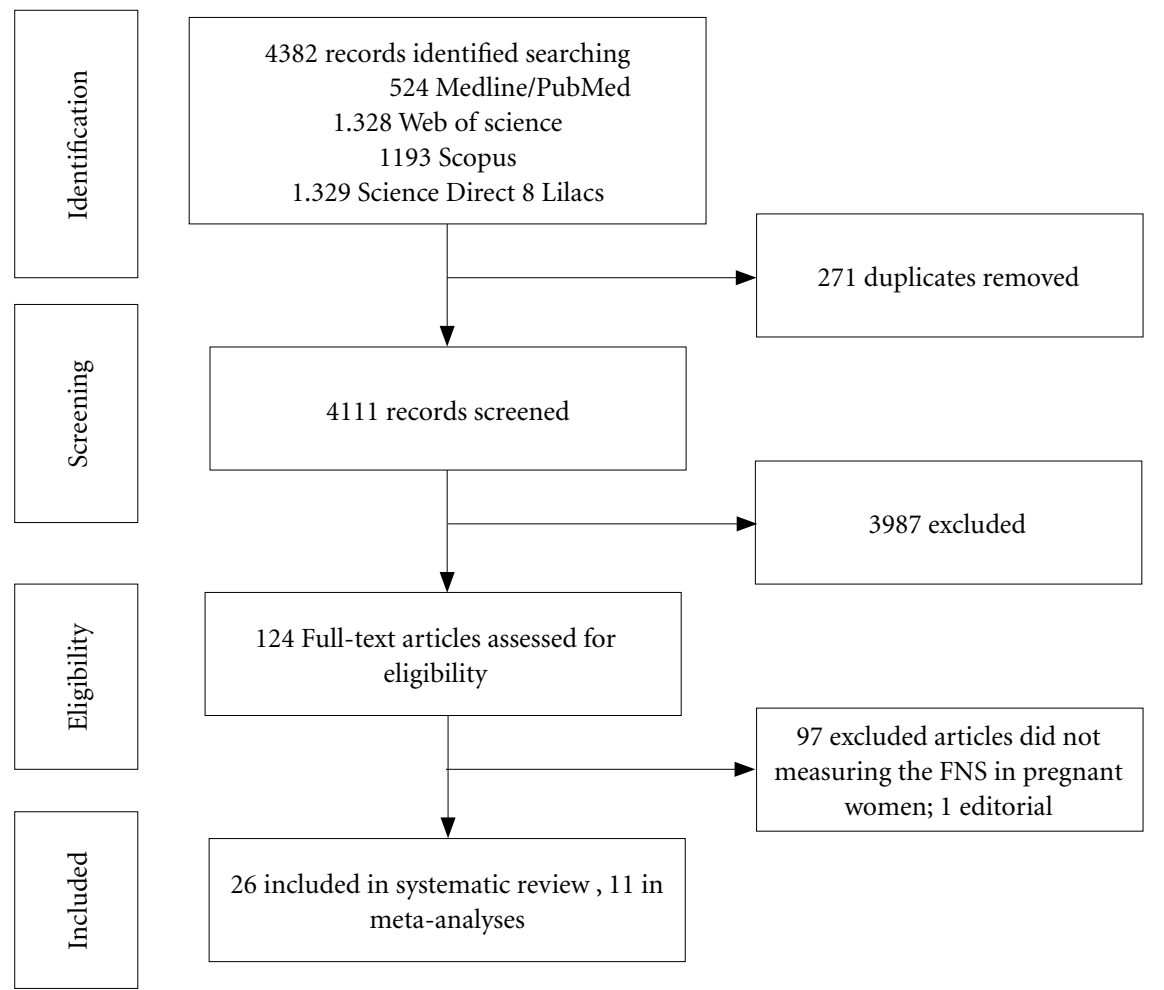

Figure 1. Flow chart for article selection.

The studies were published between 2006 and 2017, and the majority (10) of them was conducted in the United States (USA). A majority (14) used an epidemiological study design of a cross-sectional type, 7 articles used cohorts, 2 used intervention, and 2 used case control. Most of the studies used the Household Food Security Survey Module (HFSSM) as an instrument for evaluating the household food insecurity situation for women and pregnant women (Chart 2 ). Regarding the methodological quality of the studies analyzed, most (65\%) were found to have a high bias risk (Figure 2; Table 1), mainly because the final study sample was truly representative of the target population.

FI was considered as an exposure variable in most of the studies $(18)^{1,10,16,18-20,23-25,27-31,34,35,37,38}$ and the outcomes investigated were: anemia ${ }^{1,33,37}$, anthropometric nutritional status ${ }^{19,20,22,34,36}$, congenital birth defects ${ }^{10}$, mental health ${ }^{23,28,29,34,39}$, gestational complications (diabetes, hypertension $)^{18,27}$, food consumption ${ }^{22,25,31}$, and other out- comes $^{30}$. In four of the investigations ${ }^{17,22,26,39}$, FI was studied as an outcome (Chart 4).

\section{The relationship of social determinants to food insecurity for pregnant women}

In Figure 3, the social determinants that increased exposure to food insecurity in pregnant women were considered in 7 studies ${ }^{1,17,18,25,29,33,34}$. It was observed that black pregnant women had an $83 \%$ higher occurrence of FI compared to non-blacks $(\mathrm{PR}=1.83 ; 95 \% \mathrm{CI}=1.08-3.10$; Figure 3.1). A similar tendency was found for participation in social protection programs (PR $=1.43,95 \% \mathrm{CI}=1.02-2.01$; Figure 3.2), and for low education level $(\mathrm{PR}=2.73,95 \% \mathrm{CI}=1.68$ 4.43; Figure 3.3). It was also found that married pregnant women had protection against food insecurity $(\mathrm{PR}=0.61,95 \% \mathrm{CI}=0.40-0.95$; Figure 3.4). The results of the inconsistency test showed a high heterogeneity among the analyzed studies $(p=0.00)$. Therefore, the random effects model 


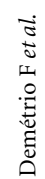

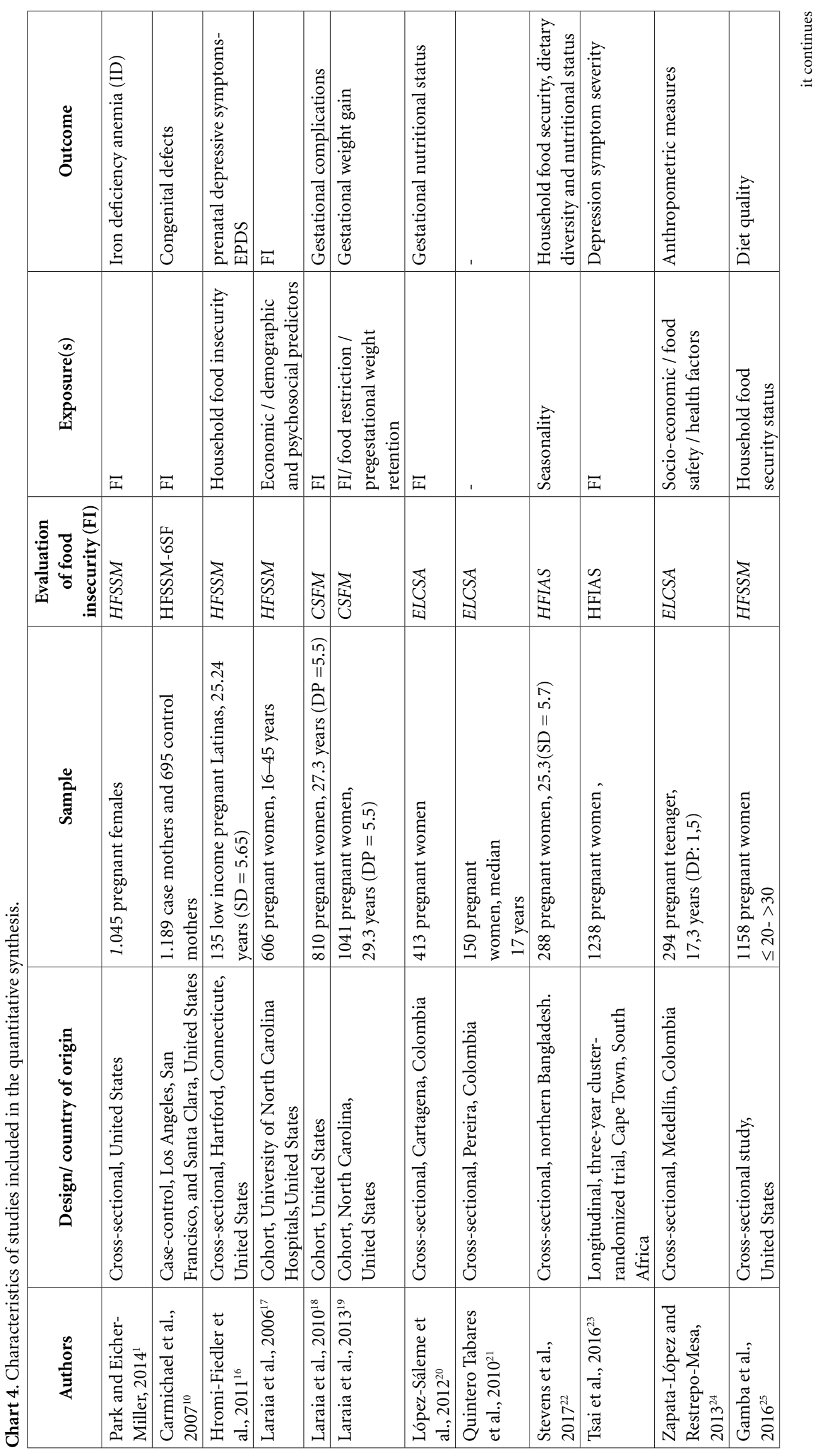




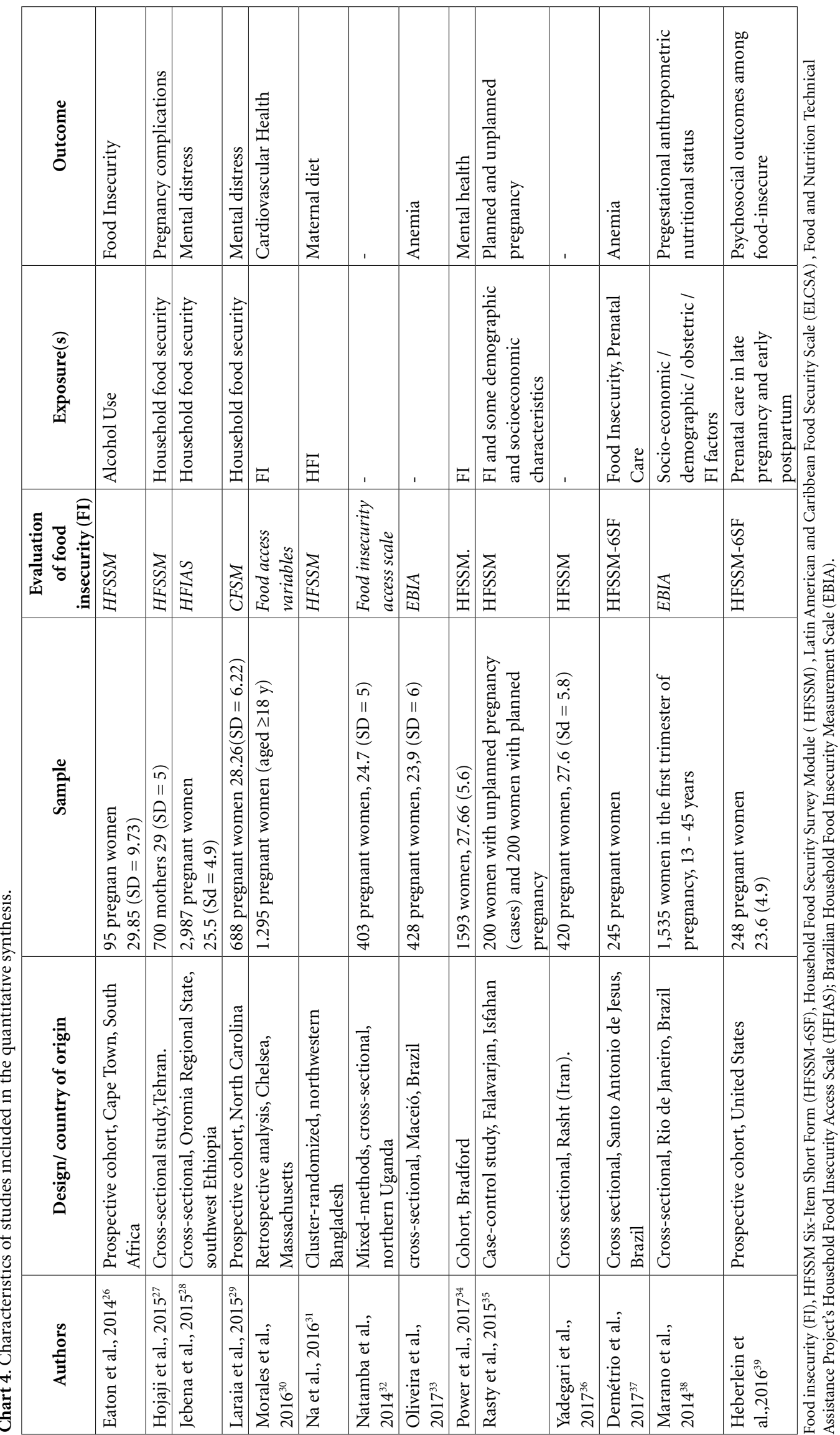




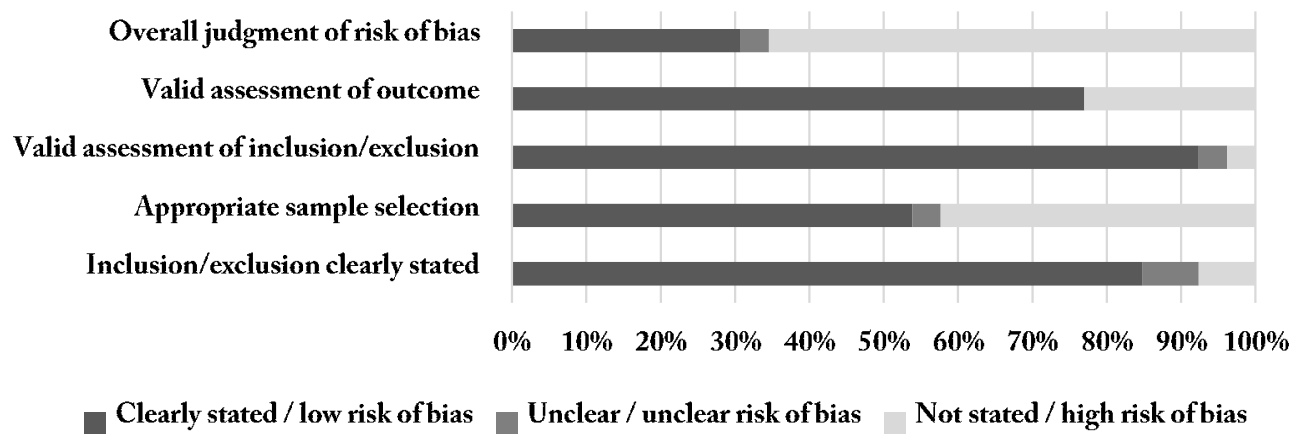

Figure 2. Risk of bias - Summary of all studies.

Table 1. Risk bias assessment using RTI Item Bank for the studies included in the meta-analysis.

\begin{tabular}{|c|c|c|c|c|c|c|c|c|}
\hline \multirow{2}{*}{ Authors } & \multicolumn{7}{|c|}{ Question Numbers } & \multirow{2}{*}{$\begin{array}{c}\text { Overall } \\
\text { Judgment on } \\
\text { Risk of Bias }\end{array}$} \\
\hline & Q1 & Q2 & Q3 & Q4 & Q5 & Q6 & Q7 & \\
\hline Carmichael et al., 2007 & + & + & + & - & + & + & + & High \\
\hline Hromi-Fiedler et al., 2011 & + & + & + & - & $?$ & + & + & High \\
\hline Laraia et al., 2006 & + & + & + & - & + & + & + & High \\
\hline Laraia et al., 2010 & + & + & + & - & + & + & + & High \\
\hline Laraia et al., 2013 & $?$ & + & + & - & + & + & + & High \\
\hline López-Sáleme et al., 2012 & - & + & + & + & + & + & - & High \\
\hline Marano et al., 2014 & + & + & + & - & + & + & + & High \\
\hline Park et al., 2014 & - & + & + & + & + & + & + & High \\
\hline Quintero et al., 2010 & + & + & + & - & + & - & - & High \\
\hline Stevens et al., 2016 & + & + & + & + & + & + & - & High \\
\hline Tsai et al., 2016 & + & + & + & + & + & + & + & Low \\
\hline Zapata-López et al., 2013 & + & + & + & + & + & + & + & Low \\
\hline Gambda et al., 2016 & + & + & + & + & + & + & + & Low \\
\hline Eaton et al., 2014 & $?$ & + & + & + & + & + & - & High \\
\hline Heberlein et al., 2016 & + & + & + & _ & + & + & + & High \\
\hline Hojaji et al., 2015 & + & + & + & - & + & + & + & High \\
\hline Jebena et al., 2015 & + & + & + & + & + & + & + & Low \\
\hline Laraia et al., 2015 & + & + & + & + & + & + & + & Low \\
\hline Morales et al., 2016 & + & + & + & + & - & - & - & High \\
\hline Na et al., 2016 & + & + & + & - & + & + & + & High \\
\hline Natamba et al., 2014 & + & + & + & $?$ & + & + & + & Moderate \\
\hline Oliveira et al., 2017 & + & + & + & + & + & + & + & Low \\
\hline Power et al., 2017 & + & + & + & + & + & + & + & Low \\
\hline Rasty et al., 2015 & + & + & + & - & + & + & + & High \\
\hline Yadegari et al., 2017 & + & + & + & + & + & + & - & High \\
\hline Demetrio et al., 2017 & + & + & + & + & + & + & + & Low \\
\hline
\end{tabular}

Key: + = low risk of bias; - = high risk of bias; ? = unclear risk of bias. 

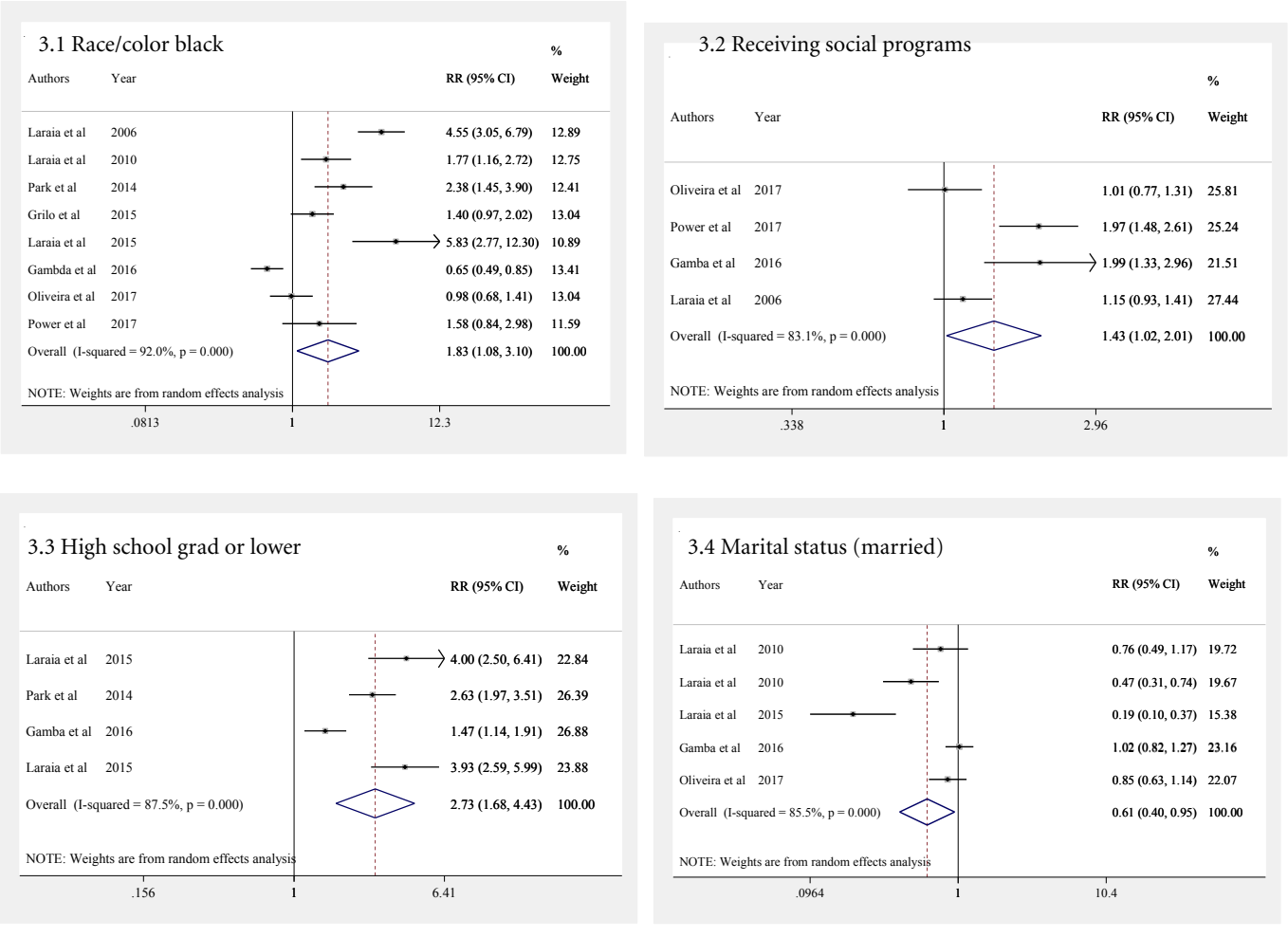

Figure 3. Association of social determinants and food insecurity in pregnant women.

was used to calculate the summary measure of associations.

\section{Food insecurity in pregnant women and nutritional outcomes}

As shown in Figure 4, food insecurity was considered to be an exposure factor for the occurrence of adverse nutritional outcomes in 7 studies $^{1,18-20,33,37,38}$. Food insecurity in the pre-gestational phase was associated with obesity (PR = $1.47,95 \% \mathrm{CI}=1.15-1.87$; Figure 4.1$)$ and overweight $(\mathrm{PR}=1.57,95 \% \mathrm{CI}=1.29$-1.91; Figure 4.2). During gestation, food insecurity increased the occurrence of both excessive weight gain (PR $=1.42,95 \% \mathrm{CI}=1.10-1.82$; Figure 4.3$)$ and inadequate weight gain $(\mathrm{PR}=1.47,95 \% \mathrm{CI}=1.09$ 1.97; Figure 4.4). FI did not have a statistically significant association with anemia during pregnancy $(\mathrm{PR}=1.28,95 \% \mathrm{CI}=0.89-1.84$; Figure 4.5).

\section{Discussion}

Many social determinants are associated with the food and nutritional security situation during pregnancy. This phase in a woman's life is a time when psychological and physiological transformations can lead to vulnerability within the context of social inequity, such as poverty and lack of coverage by social policies. The results of this study show that social determinants such as race, participation in social programs, education, and marital status are associated with an increase in the occurrence of FI in pregnant women. On the other hand, FI during the pre-gestational period increased the occurrence of being overweight or obese, and provoked an increase in both excessive and inadequate weight gain during gestation.

Over the past seventeen years (2000-2017), the number of published studies on food and nutritional safety conditions in pregnant women has increased. However, this scientific production is concentrated mostly in North American countries. The need to carry out studies on the subject in countries with different social and ep- 

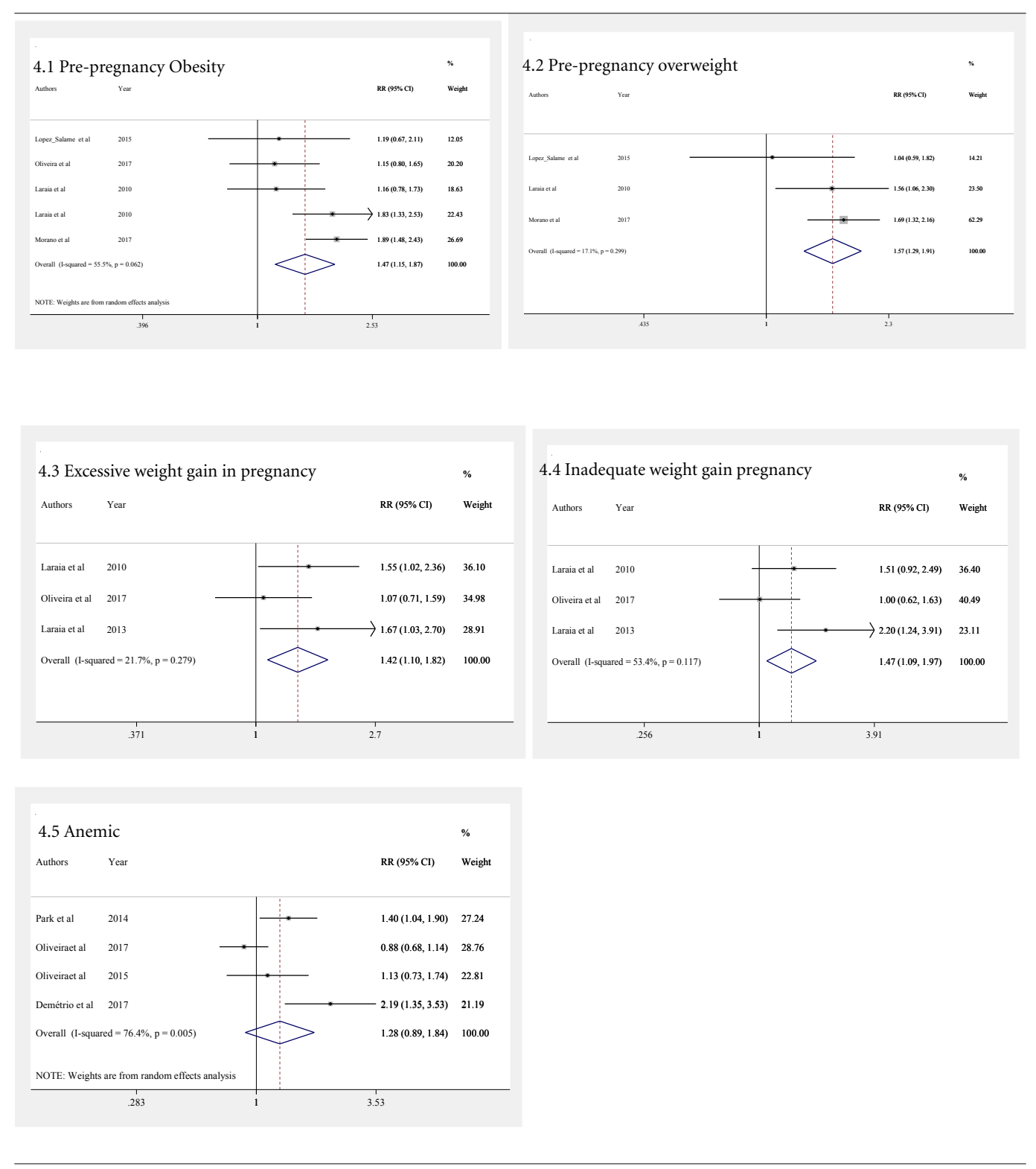

Figure 4. Food insecurity in pregnant women and nutrition outcomes.

idemiological contexts is therefore evident, considering the many negative outcomes to women's health associated with food and nutritional insecurity, especially during the gestational period. It should be emphasized, however, that most of the studies that have been carried out are cross-sectional, making it difficult to assess the repercussions of FI on women's health and nutrition. In addition, qualitative studies that investigate subjective and socio-cultural issues experienced by women facing FI are scarce. It is therefore neces- sary that future studies be conducted to consider these aspects.

Household Food Insecurity is correlated to social indicators ${ }^{1,17,18,25,29,33,34}$, especially those related to education, family income, and participation in social protection programs. However, in addition to financial constraints and adverse conditions related to poverty that make families vulnerable to HFI, racial determinants, such as black skin color, are also correlated to the condition of FNI in pregnant women ${ }^{1,17,18,25,29,33,34}$. These 
factors contribute to the violation of the right to adequate food, health, education, and housing. Therefore, social and racial inequities reinforce themselves through food and nutritional insecurity, especially when this occurs during gestation.

Social assistance programs targeting poor families may potentially be associated with FI in pregnant women ${ }^{17,25,33,34}$. This relationship indicates that social protection programs are adequately focused on pregnant women in situations of social inequality, but do not reinforce inequalities.

The present study identified that the relationship between FI and the anthropometric nutritional status of the mother was the object of greatest investigative focus among the surveys ${ }^{18-20,33,38}$. In most of these studies, FI was associated with excess weight (overweight/obesity) ${ }^{18-20,33,38}$. This demonstrates the fact that anthropometric nutritional deviations in pregnant women accompanied changes in the nutritional profile of the overall population, marked by the steady increase of obesity and food consumption, with the predominance of densely caloric foods having reduced vitamin, mineral, and antioxidant content, resulting in situations of nutritional insecurity. In this way, poorer families end up purchasing more energy-dense foods, especially in societies where these foods are cheaper ${ }^{40}$.

This change, characterized by a decrease in the occurrence of malnutrition (or underweight) along with an increase in the prevalence of being overweight and obese, corroborates the phenomena of nutritional transition in underdeveloped and developing countries, as well as in developed countries $^{19,38}$. The condition of FNI can also be associated with nutritional deficit and thinness. Thus, in contexts of severe or moderate FNI, pregnant women may experience food deprivation and hunger, contributing to thinness and insufficient weight gain during pregnancy.

FI may be especially critical during pregnan$\mathrm{Cy}^{17}$. This is because nutritional requirements increase due to physiological changes that occur in pregnant women, such as an increase in basal metabolism caused by accelerated synthesis of fetal, placenta, uterine mammary tissues, and maternal reserve, and an increase in the mass of metabolically active tissue and cardio-respiratory work. The effort necessary to prepare food may become more difficult and pregnant women may be obliged to leave work, especially at the end of the pregnancy, leading to financial restrictions. All of these factors can influence nutrition, health conditions, and nutritional status of preg- nant women and result in adverse outcomes for the pregnancy ${ }^{17}$.

It is important to note that some factors that influence maternal food insecurity ${ }^{17}$, such as the increased effort to prepare food and the "forced" abandonment of work at the end of the pregnancy, do not apply to the reality of women who have a support network during pregnancy, either from the family, or a partner or spouse. It is important to consider that pregnancy is not a phase of life effected only by biological and individual factors, but also by collective - family and socio-cultural factors. Therefore, the occurrence of FI during pregnancy and its repercussions on the health and nutrition of pregnant women also depends on the interrelations among these factors.

Both developed and developing countries, such as Brazil, have experienced changes in social and urban standards since the beginning of the $21^{\text {st }}$ century, with improvements in sanitary conditions and reduction of misery and poverty. It is possible that these standards, when considered in a neoliberal globalization context, have influenced the health and nutritional conditions of women and men differently ${ }^{41}$. In this scenario, emphasis is given to the phenomena of epidemiological and nutritional transition, in which, paradoxically, FI is associated both with infectious/contagious diseases and deficiencies, such as chronic non-transmissible diseases that mainly affect psychosocial biologically vulnerable groups, such as pregnant women ${ }^{41}$.

The relation between FI and anemia in pregnant women and those of reproductive age was another important object of investigation in the studies ${ }^{22,37}$. This relationship was confirmed in the surveys conducted by Park \& Eicher-Miller ${ }^{1}$, on North American pregnant women. Quintero Tabares et al. ${ }^{21}$ performed only a descriptive approach on the prevalence of outcomes investigated, among which anemia and FI were included.

Considering that pregnant women belong to a psycho-biologically vulnerable group, it is possible that in the context of socio-economic vulnerability and FI, the development of anemia could occur at a higher rate during pregnancy ${ }^{33,37}$. Anemia causes undesirable effects to the health of pregnant women and fetuses. This is because its occurrence during pregnancy has been associated with a higher mortality rate for mother and fetus, an increase in the risk of alterations to the immunological and cardiovascular functions of pregnant women, with a higher blood loss during birth, and a higher risk of premature birth and weight deviations at birth (low weight). Also, 
newborns may have iron reserves below normal and a higher risk of developing anemia during the first months of their lives ${ }^{33,37}$.

While investigations using a quantitative approach of an epidemiological nature were concerned with examining the association between FI and specific outcomes or identifying prevalent factors associated with FI, those using a qualitative and theoretical approach aimed to analyze and understand the interrelations between FI and both macro and microstructural factors such as neoliberal globalization and economic policies that empower women farmers, as well as aspects such as gender, psychosocial factors, culture, environment, and access to health services ${ }^{7-9}$.

\section{Limitations and future directions}

This meta-analysis has some limitations, the first being with regard to the study design. The review was dominated by cross-sectional studies, hindering the investigation between exposure to FI and the emergence of adverse nutritional outcomes and making it difficult to determine causality. Future studies on this subject should take into account the design of the prospective studies. The second limitation refers to how food insecurity was classified in the studies analyzed. It was not possible to achieve greater detail on the degree of food insecurity due to different scales used in the evaluation of the FI situation. Even considering such limitations, this is the first systematic review using meta-analysis on the relationship between FI, social determinants, and nutritional outcomes, and which emphasizes the importance of focusing on food and nutrition policies aimed at promoting and realizing the right to adequate food for pregnant women.
Regarding the methodological quality of the studies analyzed, most presented low bias risk. The main problems found with the studies were absence of sample calculations and the use of non-probabilistic sampling. It is evident that epidemiological studies with representative samples should be conducted on the association between FI, social determinants, and nutritional state in pregnant women.

A greater frequency of studies was noted reporting that black skin color, low education levels, and participation in social protection programs are consistently associated with an elevated occurrence of FI in pregnancy.

Food insecurity has important implications for the health and nutrition of individuals. FI increased the chances of both excessive weight gain and inadequate weight gain during pregnancy. Gaps remain in understanding the direction of association and causality of these events.

This review also demonstrated that scientific research on FI, gestation, and their interrelations is still scarce. FI in women encompasses a wide range of factors, from nutritional and health issues to social, cultural, economic, environmental, and political issues, indicating the importance of interdisciplinary and integrated approaches.

The development of prospective studies in different countries is recommended, in order to test the relationship between food insecurity and social determinants, mental health, and nutritional outcomes in pregnancy. The sample size should be suitable for comparison between the groups, confounding control and reverse causation assessment. Further studies are needed that may contribute towards extending the range of knowledge on the effects of FI on the health of pregnant women and of the family, and the formation of health and nutrition policies that guarantee the FNS of women during gestation. 


\section{Collaborations}

F Demetrio and M Pereira participated in the article's conception, systematic literature review, analysis, and writing and final revision. DB Santos and CAS Teles participated in the critical revision and approval of the final version.

\section{References}

1. Park CY, Eicher-Miller HA. Iron deficiency is associated with food insecurity in pregnant females in the United States: National Health and Nutrition Examination Survey 1999-2010. 1999-2010. J Acad Nutr Diet 2014; 114(12):1967-1973.

2. Larson NI, Story MT. Food insecurity and weight status among U.S. children and families: a review of the literature. Am J Prev Med 2011; 40(2):166-173.

3. Whitaker RC, Phillips SM, Orzol SM. Food insecurity and the risks of depression and anxiety in mothers and behavior problems in their preschool-aged children. Pediatrics 2006; 118(3):e859-e868.

4. Brasil. Conselho Nacional de Segurança Alimentar e Nutricional (CONSEA). A Segurança alimentar e nutricional $e$ o direito humano à alimentação adequada no Brasil. Brasília: CONSEA; 2010.

5. Instituto Brasileiro de Geografia e Estatística (IBGE). Pesquisa Nacional por Amostra de Domicílios (PNAD): segurança alimentar 2013. Brasilia: IBGE; 2014.

6. Food and Agriculture Organization (FAO). The State of Food Insecurity in the World The multiple dimensions of food security 2013. Rome: FAO; 2013.

7. Ivers LC, Cullen KA. Food insecurity: Special considerations for women. Am J Clin Nutr 2011; 94(6):1740S-1744S.

8. Abu-Saad K, Fraser D. Maternal nutrition and birth outcomes. Epidemiol Rev 2010; 32:5-25.

9. Sun J, Knowles M, Patel F, Frank DA, Heeren TC, Chilton M. Childhood adversity and adult reports of food insecurity among households with children. Am J Prev Med 2016; 50(5):561-572.

10. Carmichael SL, Yang W, Herring A, Abrams B, Shaw GM. Maternal food insecurity is associated with increased risk of certain birth defects. J Nutr 2007; 137(9):2087-2092.

11. World Health Organization (WHO). A conceptual framework for action on the social determinants of health. social determinants of health discussion paper 2. Geneva: WHO; 2010.

12. Atuoye KN, Luginaah I. Food as a social determinant of mental health among household heads in the upper west region of Ghana. Soc Sci Med 2017; 180:170-180.

13. Panic N, Leoncini E, De Belvis G, Ricciardi W, Boccia $S$. Evaluation of the endorsement of the preferred reporting items for systematic reviews and meta-analysis (PRISMA) statement on the quality of published systematic review and meta-analyses. PLoS One 2013; 8(12):e83138.

14. Viswanathan M, Berkman ND. Development of the RTI item bank on risk of bias and precision of observational studies. J Clin Epidemiol 2012; 65(2):163-178

15. Higgins JPT, Thompson SG. Quantifying heterogeneity in a meta-analysis. Stat Med 2002; 21(11):15391558.

16. Hromi-Fiedler A, Bermudez-Millan A, Segura-Perez S, Perez-Escamilla R. Household food insecurity is associated with depressive symptoms among low-income pregnant Latinas. Matern Child Nutr 2011; 7(4):421-430.

17. Laraia B, Siega-Riz AM, Gundersen C, Dole N. Psychosocial factors and socioeconomic indicators are associated with household food insecurity among pregnant women. J Nutr 2006; 136(1):177-182. 
18. Laraia BA, Siega-Riz AM, Gundersen C. Household food insecurity is associated with self-reported pregravid weight status, gestational weight gain, and pregnancy complications. J Am Diet Assoc 2010; 110(5):692-701.

19. Laraia B, Epel E, Siega-Riz AM. Food insecurity with past experience of restrained eating is a recipe for increased gestational weight gain. Appetite 2013; 65:178-184.

20. López-Sáleme R, Díaz-Montes CE, Bravo-Aljuriz L, Londoño-Hio NP, Salguedo-Pájaro MDC, Camargo-Marín CC, Osorio-Espitia E. Seguridad alimentaria y estado nutricional de las mujeres embarazadas en Cartagena, Colombia, 2011. Rev Salud Pública 2012; $14(2): 200-212$.

21. Quintero Tabares R, Muñoz Astudillo MN, Alvarez Sierra LE, Medina Perea GA. Estado nutricional y seguridad alimentaria en gestantes adolescentes. Pereira, Colombia, 2009. Investig y edicación en Enfermería 2010; 28(2):204-213.

22. Stevens B, Watt K, Brimbecombe J, Clough A, Judd $\mathrm{J}$, Lindsay D. The role of seasonality on the diet and household food security of pregnant women living in rural Bangladesh: A cross-sectional study. Public Health Nutr 2017; 20(1):121-129.

23. Tsai AC, Tomlinson M, Comulada WS, RotheramBorus MJ. Food insufficiency, depression, and the modifying role of social support: Evidence from a population-based, prospective cohort of pregnant women in peri-urban South Africa. Soc Sci Med 2016; 151:69-77.

24. Zapata-López N, Restrepo-Mesa SL. Factors associated with maternal body mass index in a group of pregnant teenagers, Medellin, Colombia. Cad Saude Publica 2013; 29(5):921-934.

25. Gamba R, Leung CW, Guendelman S, Lahiff M, Laraia BA. household food insecurity is not associated with overall diet quality among pregnant women in NHANES 1999-2008. Matern Child Health J 2016; 20(11):2348-2356.

26. Eaton LA, Pitpitan E V, Kalichman SC, Sikkema KJ, Skinner D, Watt MH, Pieterse D, Cain DN. Food insecurity and alcohol use among pregnant women at alcohol-serving establishments in South Africa. Prev Sci 2014; 15(3):309-317.

27. Hojaji E, Zavoshy R, Noroozi M, Jahanihashemi H, Ezzedin N. Assessment of household food security and its relationship with some pregnancy complications. J Maz Univ Med Sci 2015; 25(123):91-102.

28. Jebena MG, Taha M, Nakajima M, Lemieux A, Lemessa F, Hoffman R, Tesfaye M, Belachew T, Workineh N, Kebede E, Gemechu T, Tariku Y, Segni H, Kolsteren P, al'Absi M. Household food insecurity and mental distress among pregnant women in Southwestern Ethiopia: a cross sectional study design. BMC Pregnancy Childbirth 2015; 15:250.

29. Laraia B, Vinikoor-Imler LC, Siega-Riz AM. Food insecurity during pregnancy leads to stress, disordered eating, and greater postpartum weight among overweight women. Obesity 2015; 23(6):1303-1311.

30. Morales ME, Epstein MH, Marable DE, Oo SA, Berkowitz SA. Food insecurity and cardiovascular health in pregnant women: results from the food for families program, Chelsea, Massachusetts, 2013-2015. Prev Chronic Dis 2016; 13:E152.
31. Na M, Mehra S, Christian P, Ali H, Shaikh S, Shamim AA, Labrique AB, Klemm RD, Wu LS, West Junior KP. Maternal dietary diversity decreases with household food insecurity in rural Bangladesh: A longitudinal analysis. J Nutr 2016; 146(10):2109-2116.

32. Natamba BK, Kilama H, Arbach A, Achan J, Griffiths JK, Young SL. Reliability and validity of an individually focused food insecurity access scale for assessing inadequate access to food among pregnant Ugandan women of mixed HIV status. Public Health Nutr 2014; 18(16):2895-2905.

33. Oliveira ACM, Tavares MCM, Bezerra AR. Insegurança alimentar em gestantes da rede pública de saúde de uma capital do nordeste brasileiro. Cien Saude Colet 2017; 22(2):519-526.

34. Power M, Uphoff E, Kelly B, Pickett KE. Food insecurity and mental health: An analysis of routine primary care data of pregnant women in the Born in Bradford cohort. J Epidemiol Community Health 2017; 71(4):324-328.

35. Rasty R, Pouraram H, DorostyMotlagh A, Heshmat R. Food insecurity and some demographic and socioeconomic characteristics, fertility, and pregnancy in women with planned and unplanned pregnancy. Iran J Epidemiol 2015; 11(3):34-42.

36. Yadegari L, Dolatian M, Mahmoodi Z, Shahsavari S, Sharifi N. The relationship between socioeconomic factors and food security in pregnant women. Shiraz E Med J 2017; 18(1):e41483.

37. Demétrio F, Teles-Santos CAS, Santos DB. Insegurança alimentar, cuidado pré-natal e outros determinantes da anemia em mulheres grávidas da coorte $\mathrm{Ni}$ sami, Brasil: Modelo conceitual hierárquico. Rev Bras Ginecol e Obstet 2017; 39(8):384-396.

38. Marano D, Gama SGN, Domingues RMSM, Souza Júnior PRB. Prevalence and factors associated with nutritional deviations in women in the pre-pregnancy phase in two municipalities of the state of Rio de Janeiro, Brazil. Rev Bras Epidemiol 2014; 17(1):45-58.

39. Heberlein EC, Frongillo EA, Picklesimer AH, Covington-Kolb S. Effects of Group Prenatal Care on Food Insecurity during Late Pregnancy and Early Postpartum. Matern Child Health J 2016; 20(5):1014-1024.

40. Darmon N, Drewnowski A. Contribution of food prices and diet cost to socioeconomic disparities in diet quality and health: a systematic review and analysis. Nutr Rev 2015; 3(10):643-660.

41. Popkin BM, Adair LS, Ng SW. Global nutrition transition and the pandemic of obesity in developing countries. Nutr Rev 2012; 70(1):3-21.

Article submitted 03/03/2018

Approved 15/11/2018

Final version submitted 18/11/2018 